\title{
FATIGUE PARAMETER CHANGE OF OPTICAL FIBER WITH TEMPERATURE VARIATION
}

\author{
R. El Abdi ${ }^{1}$, R. Leite Pinto ${ }^{1}$, G. Guérard, C. Capena ${ }^{2}$ \\ ${ }^{1}$ Univ. Rennes- CNRS, Institut de Physique de Rennes. UMR 6251. F-35000 Rennes, France \\ ${ }^{2}$ Entreprise Acom - Usines de Mortain, 50140 Mortain, France \\ Email: relabdi@univ-rennes1.fr
}

\begin{abstract}
Besides signal transmission for telecommunications, optical fibers are used in an increasing number of devices. A number of applications relate to devices exposed to severe wet environment (hot water, chemical attacks, etc.). Fiber failure is an irreversible accident which may occur when an external stress is applied on a defect located on the fiber surface. External environment as humidity and water is a major factor for the crack propagation on the fiber glass surface because it facilitates the breaking of the silica bonds of the fiber cladding. Water influence becomes more damaging when the water is brought to a high temperature.

In this work, new silica optical fibers wounded around ceramic mandrels with different diameters and aged in hot water were tested to obtain the fatigue parameter changes.

Temperature dependence of failure time, the stress corrosion parameter versus temperature and the activation energy change were analyzed to obtain an aging behavior law. On the other hand, Weibull distribution showed the temperature had an important role of optical fiber strength weakening.
\end{abstract}

Keywords: Temperature effect, Optical fibers, Bending tests, Activation energy, Failure time.

\section{Introduction}

Optical fibers are key components in telecommunication technologies. Apart from optical specifications, optical fibers are expected to keep most of their physical properties for 10 to 20 years in current operating conditions. Fiber failure makes an irreversible accident which may occur when an external stress is applied on a defect located on fiber surface. While intrinsic defects, referred to as Griffith flaws, lead to failure only for large applied stresses, other heterogeneous defects make a far more serious concern as they lead to the fiber failure of the aged fibers under moderate stress. The fabrication process includes a proof test that eliminates the largest defects. However, the chemical action of water is likely to induce stress corrosion in the long term and to promote fiber aging.

Polymer coatings are currently applied to optical fibers to prevent the formation of surface defects through scratches and abrasion and to minimize the influence of the pre-existing defects. They also act as a diffusion barrier against the surrounding humidity reaching the glass surface. Water is known to be one major factor of the propagation of cracks at fiber glass surface because it makes much easier the breaking of the $\mathrm{Si}-\mathrm{O}$ bonds which build the vitreous network [1]. Accordingly, fiber strength is closely related to the water concentration at the glass surface [2]. It is well known that flaws in glass subject to stress in humid conditions grow subcritically. Crack velocity is related to applied stress and also to relative humidity [3]. It has also been reported that the kinetics of the reaction between silica and water changes at very low water concentration $[4,5]$. On the other hand, the temperature effects accentuate the damage when fibers were submitted to combined thermomechanical stresses.

In this work, optical fibers were wound around ceramic mandrels and aged in distilled water at different temperatures to evaluate the influence of the static bending stresses and the temperature on the fiber lifetime.

Change of different physical fiber parameters were analyzed with temperature variations.

\section{Used Test Bench}

The used single mode silica optical fibers with thick dual acrylate coating have $242 \mu \mathrm{m}( \pm 5 \mu \mathrm{m})$ in diameter, a cladding with $125 \mu \mathrm{m}( \pm 0.7 \mu \mathrm{m})$ in diameter and a zero dispersion wavelength from $1300 \mathrm{~nm}$ to $1324 \mathrm{~nm}$ (zero dispersion slope $\leq 0.092$ $\left.\mathrm{ps} / \mathrm{nm}^{2} \cdot \mathrm{km}\right)$.

Optical fiber was wound onto a ceramic mandrel of 2.8, 3, 3.2 and $3.4 \mathrm{~mm}$ in diameter (Fig. 1). The winding of each fiber was automated and the same 
applied stress was obtained for each fiber. The real deformation for each fiber depends on the mandrel diameter and each fiber has taken on the exact shape of the mandrel (Fig. 1).

Once the fiber was wound around the mandrel, it was placed between a transmitter $\mathrm{T}$ and a light receiver $\mathrm{R}$ (Fig. 1). The light beam cannot reach the receiver and from then on the time of fiber loading is triggered. The mean time to failure is recorded, and this corresponds to the time required for the fiber strength to degrade until it equals the stress applied through winding round the mandrel. The time to failure is measured by optical detection when the ceramic mandrel moves out of the special holder. When fiber breaks, the mandrel rocks from its vertical static position, the light beam can reach the receiver and the time to failure is directly recorded with an accuracy of $\pm 1 \mathrm{~s}$. The testing setup consists of a large number of vats containing 16 holders each. The fibers (wound around a mandrel) are aged in water at different temperatures.

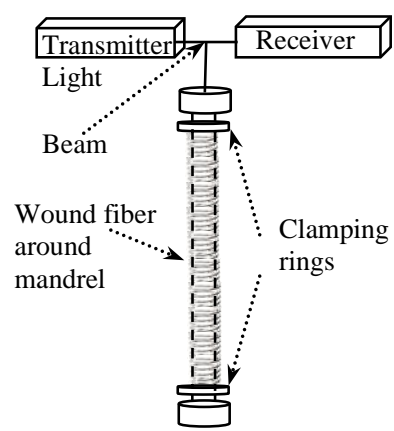

Figure 1: Ceramic mandrel with wound fibers

\section{Theoretical Background}

The Weibull theory is one of the most used methods to characterize the failure of optical fibers [6]. The statistical Weibull law gives a relationship between the probability $F$ of fiber rupture with a length $L$ and the applied stress $\sigma$.

$$
\operatorname{Ln}\left[\frac{1}{L}\left\{\operatorname{Ln}\left(\frac{1}{(1-F)}\right)\right\}\right]=m[\operatorname{Ln}(\sigma)-\operatorname{Ln}(\sigma o)]
$$

where $m$ is a size parameter and $\sigma_{o}$ is a scale parameter.

The evolution of

$$
\operatorname{Ln}\left[\frac{1}{L}\left\{\operatorname{Ln}\left(\frac{1}{(1-F)}\right)\right\}\right]
$$
according to $\operatorname{Ln}(\sigma)$ is called Weibull diagram.

This diagram enabled us to calculate $m$ and $\sigma_{o}$ which respectively correspond to the curve slope and to the curve intersection with the stress axis.

The $m$ parameter characterizes the defect size dispersion [7]. A high $\mathrm{m}$ value indicates that along the fiber the defects sizes are averaged. A low $\mathrm{m}$ value reveals that the defects found at the fiber surface have varying sizes, which results in different values of the failure stress. As to the $\sigma_{o}$ parameter, it represents the stress for which the cumulated rupture probability of the fiber $F$ is equal to $50 \%$.

To plot the Weibull diagram, which corresponds to a fiber thus characterizing a defect population, a series of mechanical tests were carried out on a great number of samples of this fibre (in practice about thirty samples were tested). All the samples were the same length $L$. Once the tests were carried out, by ascending order:

$$
\sigma_{1} \leq \sigma_{2} \leq \ldots . \leq \sigma_{l} \leq \sigma_{l+1} \leq \ldots . \leq \sigma_{N}
$$

( $N$ is the total number of tested samples).

The obtained breaking stresses were classified. For each breaking stress $\sigma_{i}$, a rupture probability $F i$ is affected using the following estimator:

$$
F_{i}=\frac{i-0.5}{N}
$$

If the rupture is characterized by a single defect category, $\operatorname{Ln}[(1 / \operatorname{L})\{\operatorname{Ln}(1 /(1-F))\}]$ varies in a linear way with $\operatorname{Ln}(\sigma)$ and Weibull modulus is given by the slope of this curve. But when the tests are carried out with large fibers lengths, one observes a slope break indicating the passage of a defect distribution to another.

On the other hand, the stress-strain relation of optical fibers was first examined by Mallinder and Proctor [8]. They found that the applied stress $\sigma(\mathrm{GPa})$ for an optical fiber is related nonlinearly to the strain $\varepsilon$ (where both $\sigma$ and $\varepsilon$ are positive in the tensile region), according to:

$$
\sigma=E_{0} . \varepsilon\left(1+\frac{\alpha^{\prime} \cdot \varepsilon}{2}\right)
$$

where $E_{0}$ is the Young modulus $(=72 \mathrm{GPa}$ for the silica); $\alpha^{\prime}=0.75 \alpha$. A value for the non-linearity constant $\alpha$ of 6 can be used [9].

One can note that a wound fiber was subjected to compressive stresses on its internal part (fiber surface close to the curvature center) and a tensile stress on its external part (fiber surface furthest away from the curvature center).

A tensile stress is experienced by the outer surface of the fiber. The bending stress must first be calculated from the mandrel diameter $\phi$. This can be performed with (4) and the simple expression for the maximum strain $\varepsilon$ [10]:

$$
\varepsilon=\frac{d_{\text {glass }}}{\phi+d_{\text {fiber }}}
$$

$\phi$ is the mandrel diameter (in $\mu \mathrm{m}$ ); $d_{\text {glace }}$ is the glass fiber diameter $(125 \mu \mathrm{m}) ; d_{\text {fiber }}$ is the fiber diameter $(242 \mu \mathrm{m})$, including the layer polymer coating. This leads, in the case of a usual fiber, to the corresponding stresses of $3.13 \mathrm{GPa}$ for the calibrated diameter mandrel of $2.8 \mathrm{~mm}$. 


\section{Results and Discussion}

\section{- Environment influence}

For different mandrel diameters, fibers were aged in air and distilled water at $20^{\circ} \mathrm{C}$. Fig. 2 shows that the water weakens the fibers and a significant number of water molecules diffused on the cladding leading to reaction between silica network and water molecules. The ratio between times to failure for aging in the air and in the water was about 4.

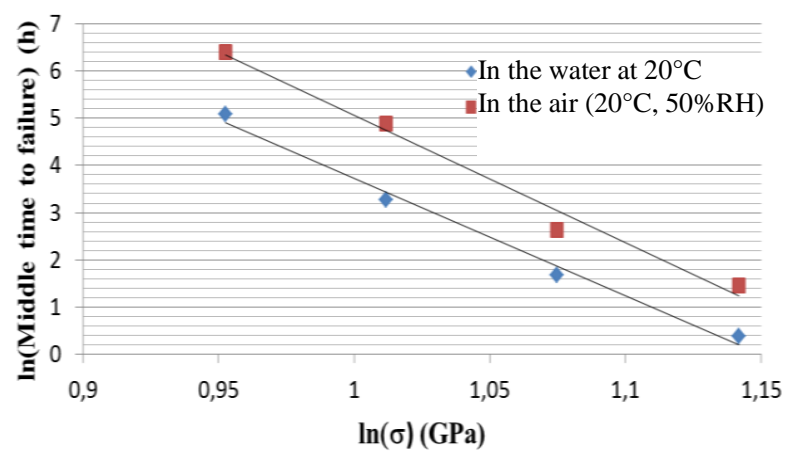

Figure 2: Time to failure for fibers aged in air and in distilled water at $20^{\circ} \mathrm{C}$

\section{- Temperature dependence of failure time}

Fibers rolled around different mandrel diameters $(2.8 \mathrm{~mm} ; 3.0 \mathrm{~mm} ; 3.2 \mathrm{~mm}$ and $3.4 \mathrm{~mm})$ were aged in hot water for different temperatures $\left(20^{\circ} \mathrm{C}, 30^{\circ} \mathrm{C}\right.$, $40^{\circ} \mathrm{C}, 50^{\circ} \mathrm{C}, 60^{\circ}$ and $70^{\circ} \mathrm{C}$ ). Weibull plot curves for water temperature of $20^{\circ} \mathrm{C}$ and $70^{\circ} \mathrm{C}$ are given in Figs 3 and 4 .

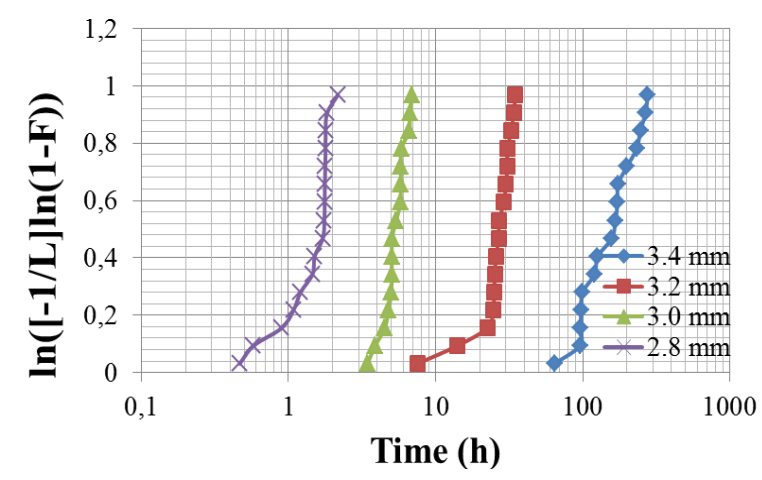

Figure 3: Weibull's diagram for fibers aged in distilled

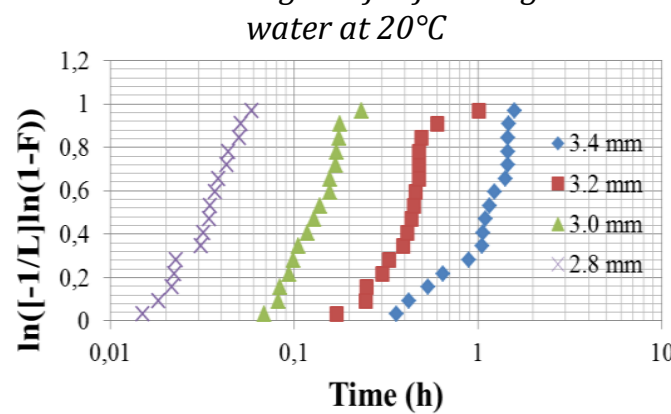

Figure 4: Weibull's diagram for fibers aged in distilled water at $70^{\circ} \mathrm{C}$

Temperature plays an essential role in fiber strength weakening. One can note for example for the mandrel diameter of $3.0 \mathrm{~mm}$, the median time to failure was equal to 30 hours when water temperature was $20^{\circ} \mathrm{C}$ and 0.5 hour when water temperature was $70^{\circ} \mathrm{C}$.

Matthewson and Kurkjian [11] found that the time to failure is therefore inverse Arrhenius:

$$
t_{f}=C \cdot \exp \left(\frac{Q}{R T}\right)
$$

where $Q$ is the apparent activation energy and $R$ is the perfect gas constant $\left(R=8.314 \mathrm{~J} \mathrm{~mol}^{-1} \mathrm{~K}^{-1}\right)$. Eq. (6) shows the high sensitivity of the silica fiber strength resistance as a function of the temperature change.

On the other hand, using experimental results, we can obtain the time to failure change according to the temperature (Fig. 5). For each value, the standard deviation was about $8 \%$.

Whatever the mandrel diameter, the logarithm of time to failure increases linearly according to the inverse of temperature as following:

$$
\ln \left(t_{f}\right)=a \cdot\left(\frac{1000}{T}\right)+b
$$

Eroare! Obiectele nu se creează din editarea codurilor de câmp.

Using Eq. (6), $Q$ values can be obtained $(Q=1000$ a. $R$ ). Table 1 summarizes $C$ and $Q$ values. The strain slowly decreases but remains around $3.7 \%$. The activation energy increases when stress increases from $61 \mathrm{~kJ} / \mathrm{mol}$ to $82 \mathrm{~kJ} / \mathrm{mol}$.

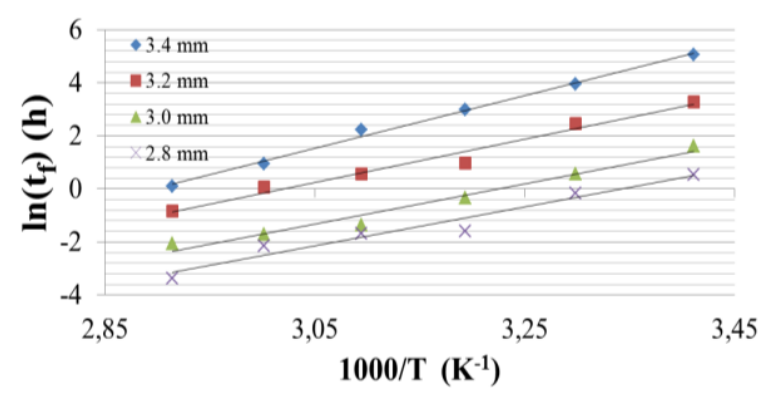

Figure 5: Time to failure in inverse proportion to temperature for different diameters

Table 1. $Q$ and $C$ values versus applied stresses

\begin{tabular}{|c|c|c|c|c|}
\hline $\begin{array}{c}\text { Mandrel } \\
\text { diameter } \\
(\mathbf{m m})\end{array}$ & $\begin{array}{c}\text { Applied } \\
\text { stress } \\
(\mathbf{G P a})\end{array}$ & $\begin{array}{c}\text { Deformation } \\
\boldsymbol{\varepsilon}(\boldsymbol{\%})\end{array}$ & $\begin{array}{c}\boldsymbol{Q} \\
(\mathbf{k J} / \mathbf{m o l})\end{array}$ & $\begin{array}{c}\boldsymbol{C} \\
(\mathbf{h})\end{array}$ \\
\hline 2.8 & 3.13 & 4.1 & 61.16 & $2.09 .10^{-11}$ \\
3 & 2.93 & 3.8 & 63.19 & $2.2810^{-11}$ \\
3.2 & 2.75 & 3.6 & 67.71 & $1.9610^{-11}$ \\
3.4 & 2.59 & 3.4 & 82.62 & $3.1510^{-13}$ \\
\hline
\end{tabular}

\section{- Change of failure time according to applied} stress

The fatigue curves according to the temperature were given in Fig. 6. Two remarks can be made:

(1) The fiber lifetime roughly decreases when temperature increases: for an applied stress $\sigma$ of $3.13 \mathrm{GPa}(\operatorname{Ln}(\sigma)=1.14 \mathrm{GPa})$, the lifetime decreases from $103 \mathrm{~min}$ to $2 \mathrm{~min}$ when the aging temperature increases from $20^{\circ} \mathrm{C}$ to $70^{\circ} \mathrm{C}$. 
(2) All the fatigue curves can be described using straight lines. This linear behavior was not obtained when the temperature was greater than $80^{\circ} \mathrm{C}$. Cuellar et al [12] observed a change in the curve slope for fibers aged at $85^{\circ} \mathrm{C}$ under a stress of 2.7 $\mathrm{GPa}$. But for a temperature lower than $70^{\circ} \mathrm{C}$ and during all the other aging tests, the coating doesn't undergo significant damage and the optical behavior remains linear.

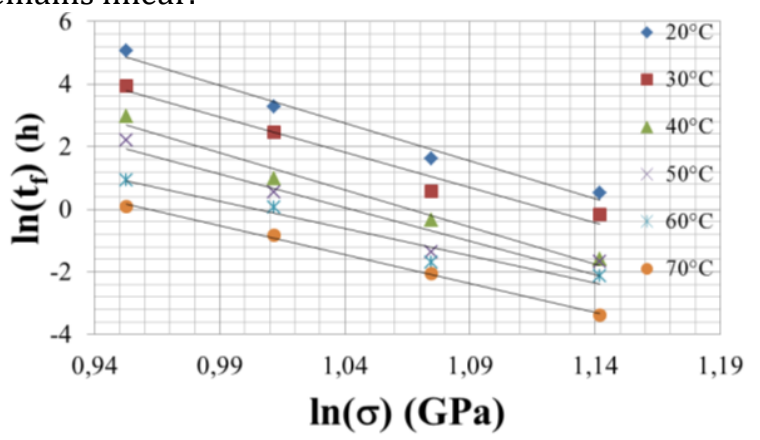

Figure 6: Time to failure according to applied stress for different temperatures

\section{- Stress corrosion parameter versus temperature}

Stress corrosion parameter $n$ is one of important values which characterize the fiber reliability.

The generally accepted corrosion parameter, $n$, is 20 for high strength fiber [13].

Equation (9) gives the stress corrosion parameter [6] which is the opposite of the curve slope:

$$
\ln \left(t_{f}\right)=-n \cdot \ln \sigma+a
$$

The $n$ values were determined through experimental results. Figure 7 shows a decreasing behaviour according to temperature. This parameter $(n)$ can be expressed as a linear function of the inverse of temperature $(1 / T)$ :

$$
n(T)=\frac{a_{O}}{T}+b_{O}
$$

where $a_{o}=9371.5 K$ and $b_{o}=-8.03$

A high stress parameter $n$ involves a great sensibility to applied stresses.

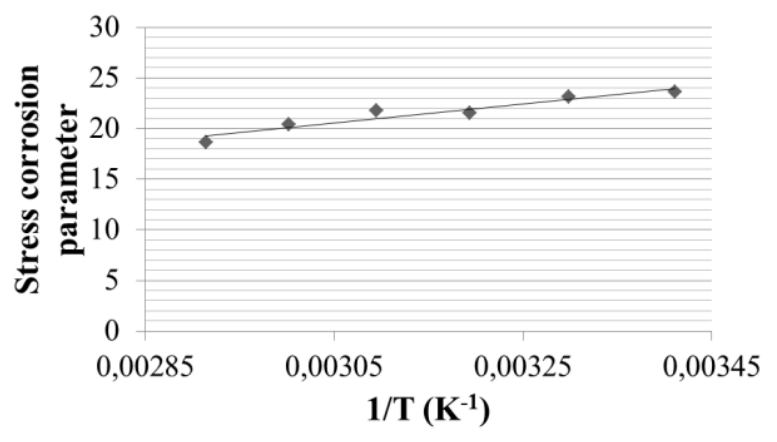

Figure 7: Stress corrosion parameter $n$ versus inverse temperature
A linear dependence of time to failure was observed for the fatigue of silica optical fibers as predicted by the exponential law. The apparent activation energy and the others fiber parameters as the stress corrosion parameter were summarized for all temperature-dependent fatigue data. This survey illustrates the temperature-dependent fatigue data for optical fibers aged in hot water and under bending stresses; these data are critical because they are a standard for all other studies.

\section{References}

[1] Adams, R., McMillan, P.W.: Review static fatigue in glass. J. of Mat. Sci., 12, 643-657 (1977).

[2] Gurney, C.: Delayed fracture in glass, Proc. Phys. Soc., London, 59, 169-185 (1947).

[3] Wiederhorn, S.M.: Influence of water vapor on crack propagation in soda-lime glass. J. Am. Ceram. Soc., 50, 407-414 (1967).

[4] Duncan, W. J., France, P.W. and Craig, S.P.: Strength of inorganic glass. Edited by C.R. Kurkjian, Plenum Press, New-York: The effect of environment on the strength of optical fiber, 351 (1985).

[5] Mrotek, J.L., Matthewson, M.J. and Kurkjian, C.R.: Diffusion of moisture through optical fiber coatings. J. Lightwave Tech., 19 (7), 988- 993 (2001).

[6] Pinto Leite, R. : Caractérisation physique et thermo-mécanique et analyse de la fiabilité des fibres optiques à base de silice, Thèse de doctorat de l'Université de Rennes1, Rennes, Juin (2019).

[7] Zhao, F.M., Okabe, T. and Takeda, N.: The estimation of the statistical fiber strength by fragmentation tests of single-fiber composites. Comp. Sc. \& Tech., 60, 1965-1974 (2000).

[8] Mallinder, F. P., Proctor, B.A.: Elastic constants of fused silica as a function of large tensile strain. Phys. Chem. Glass, 5, 91-103 (1964).

[9] Glaesemann, G.S., Gulati, S.T., Helfinstine, J.D.: Effect of strain and surface composition on Young's modulus of optical fibers. Techn. Digest, 11th OFC, TUG5, 26 (1988).

[10] Griffioen, W.: Optical fiber reliability. Thesis edited by Royal PTT Netherlands NV, PTT Research, Leidschendam, (1994).

[11] Matthewson, M.J. and Kurkjian, C.R.: Environmental effects on the static fatigue of silica optical fiber. J. Am. Ceram. Soc., 71 (33), 177-183 (1988).

[12] Cuellar, E., Kennedy, M.T., Roberts, D.R., and Ritter, J.E.: Zero stress aging and the static fatigue transition in optical fibers. Proceeding of the Society of Photo-Optical Instrumentation Engineers, 1791, 7-17 (1992).

[13] Matthewson, M.J.: Optical fiber reliability models, Fiber optics reliability and testing. SPIE Critical Reviews of Optical Science and Technology, CR50, 3-31 (1993).

\section{Conclusion}

